\title{
Indoor and Outdoor Temperature Impact on Residential Consumption - A Study in Greece
}

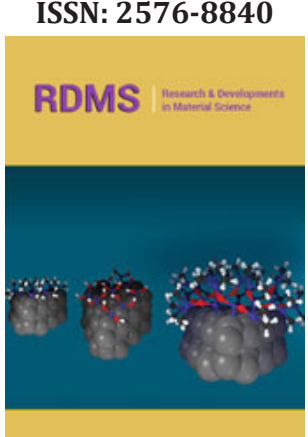

*Corresponding author: Asimina Dimara, Information Technologies Institute, Centre for Research and Technology - Hellas, Thessaloniki, Greece

Submission: 梅 September 09, 2019

Published: 踾September 19, 2019

Volume 11 - Issue 5

How to cite this article: Dimara A, Timplalexis C, Krinidis S, Tzovaras D. Indoor and Outdoor Temperature Impact on Residential Consumption - A Study in Greece. Res Dev Material Sci. 11(5). RDMS.000772.2019.

DOI: 10.31031/RDMS.2019.11.000772

Copyright@ Asimina Dimara, This article is distributed under the terms of the Creative Commons Attribution 4.0 International License, which permits unrestricted use and redistribution provided that the original author and source are credited.
Asimina Dimara*, Christos Timplalexis, Stelios Krinidis and Dimitris Tzovaras Information Technologies Institute, Centre for Research and Technology - Hellas, Thessaloniki, Greece

\section{Opinion}

Global warming and energy demand are two of the most significant factors that affect the standard of living. The temperature deviations affect energy consumed for heating or cooling a place and the emissions produced by the means used to heat and cool a building affect the climate change. This bidirectional relationship between energy and temperature needs to be examined as the demand for energy is increasing and as a result there will be a supply shortage [1]. In addition, the effects from the temperature increase are getting worse by the year [2]. The visibility provided to the consumers by the information delivered from daily consumption metering can help them to save energy and money. Consumption information can be provided by smart meters as they are easy to install, they send real time energy consumption both to the energy supplier and the consumers [3].

Smart meters were installed to residential electric central panels to monitor the energy consumption, indoor temperature sensors were used to collect indoor temperature and a weather API was exploited to gather outdoor temperature (Figure 1).

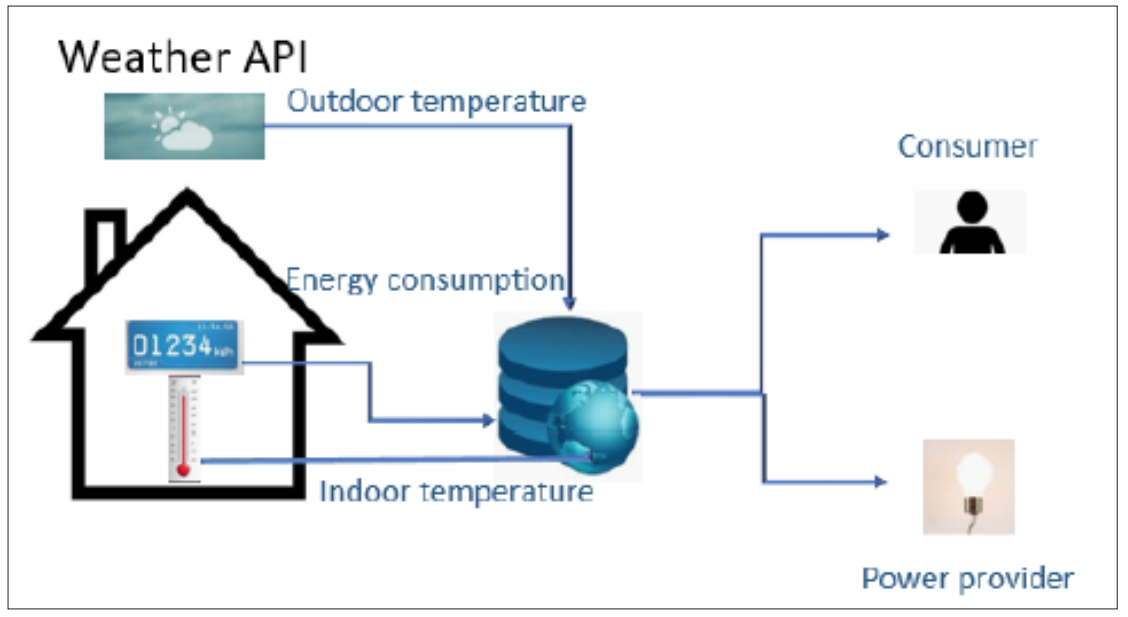

Figure 1: System abbreviated architecture.

Table 1: Experiment information.

\begin{tabular}{|c|c|}
\hline Period of study & September 2018- August 2019 \\
\hline Location & Thessaloniki Greece \\
\hline Type of buildings & Apartment, independent house, terraced house, semi-detached \\
\hline Number of households & 120 \\
\hline Heating type & Electricity, Natural Gas, Home heating oil, Wood(fireplace) \\
\hline
\end{tabular}

To study the variations of the residential consumption patterns both indoor and outdoor temperature need to be taken into account in order to analyze the degree that temperature alternations influence the consumption patterns. Using the monitored consumption data 
and temperature data, consumption deviations can be interpreted. The consumption patterns have changes similar to the outside temperature alterations and appear to have seasonal adjustments [4] (Table 1).

Table 2: Average temperature information.

\begin{tabular}{|c|c|c|}
\hline Month & January 2019 & June 2019 \\
\hline $\begin{array}{c}\text { Average daily } \\
\text { Outdoor temperature }\end{array}$ & $8.29^{\circ} \mathrm{C}$ & $31.16^{\circ} \mathrm{C}$ \\
\hline $\begin{array}{c}\text { Average daily indoor } \\
\text { temperature }\end{array}$ & $21.33^{\circ} \mathrm{C}$ & $25.33^{\circ} \mathrm{C}$ \\
\hline
\end{tabular}

Typical daily average household consumptions from a month with low temperatures (January) and high temperatures (June) were compared to daily average outdoor and indoor temperatures (Table 2).

The increase of outdoor temperature in June has a prompt impact on the amount of the energy used which is proportional to the temperature rise as depicted in Figure 2. The maximum energy consumed is $0.36 \mathrm{KWh}$ and it is spent during the time the temperature is at its largest value which was $35{ }^{\circ} \mathrm{C}$ for June. Furthermore, the minimum energy used is $0.21 \mathrm{Kwh}$ and is consumed when the temperature is at its lowest value which was $25{ }^{\circ} \mathrm{C}$. There is a direct correlation between outdoor temperature and load trend [5].

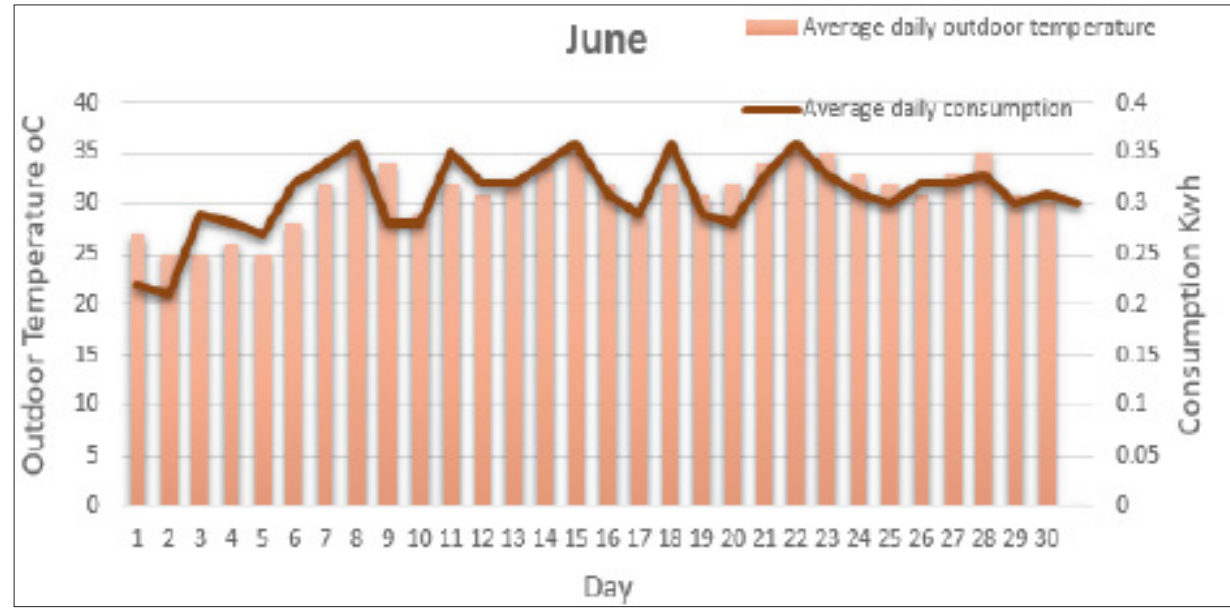

Figure 2: Average outdoor temperature and consumption in June.

The indoor temperature in June has not the same influence on energy consumption as the outdoor temperature. The increase or decrease of the monitored indoor temperature does not seem to have an equivalent change to the average consumption (Figure 3). Maximum and minimum values of consumption are irrelevant to the increase and decrease of indoor temperature.

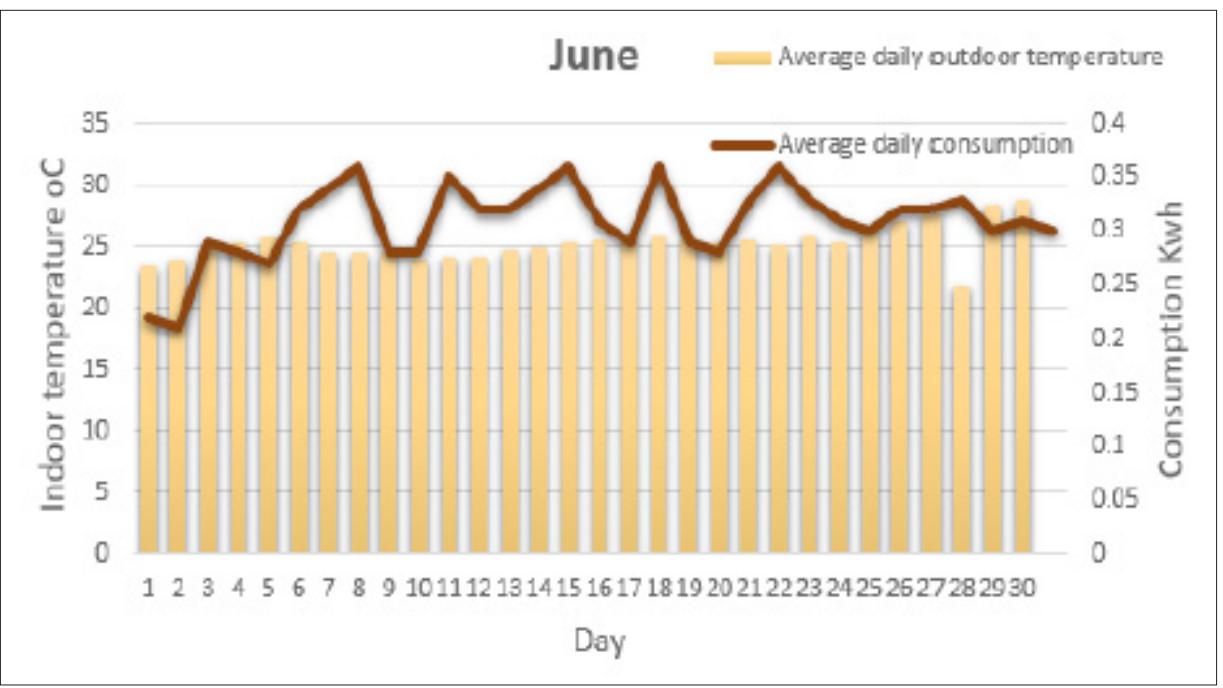

Figure 3: Average indoor temperature and consumption in June.

The findings of the energy used during the winter and low outdoor temperatures are not equivalent to the high temperatures during the summer. The deviations of the temperature are not according to consumption fluctuations. During the coldest day $\left(1{ }^{\circ} \mathrm{C}\right)$ the consumption was not the maximum. The maximum consumption appears during a day that was almost the hottest of January (Figure 4). 


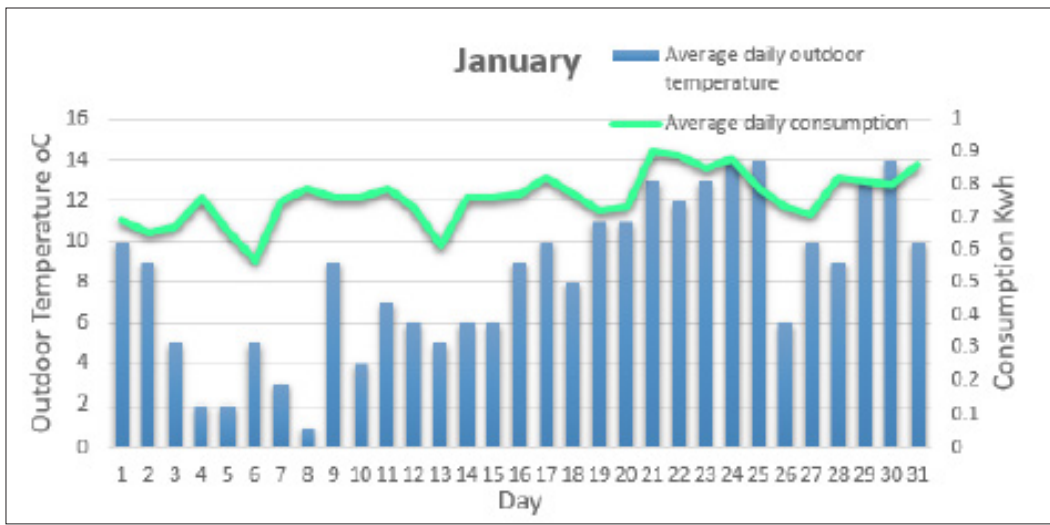

Figure 4: Average outdoor temperature and consumption in January.

On the contrary, the consumption patterns of indoor temperature during the winter follow almost the same trend. The hotter the temperature is in the room the more energy is used
(Figure 5). It may be concluded that outdoor temperature impacts more on consumption needed to cold a building and indoor temperature influences more the consumption needed to heat it.

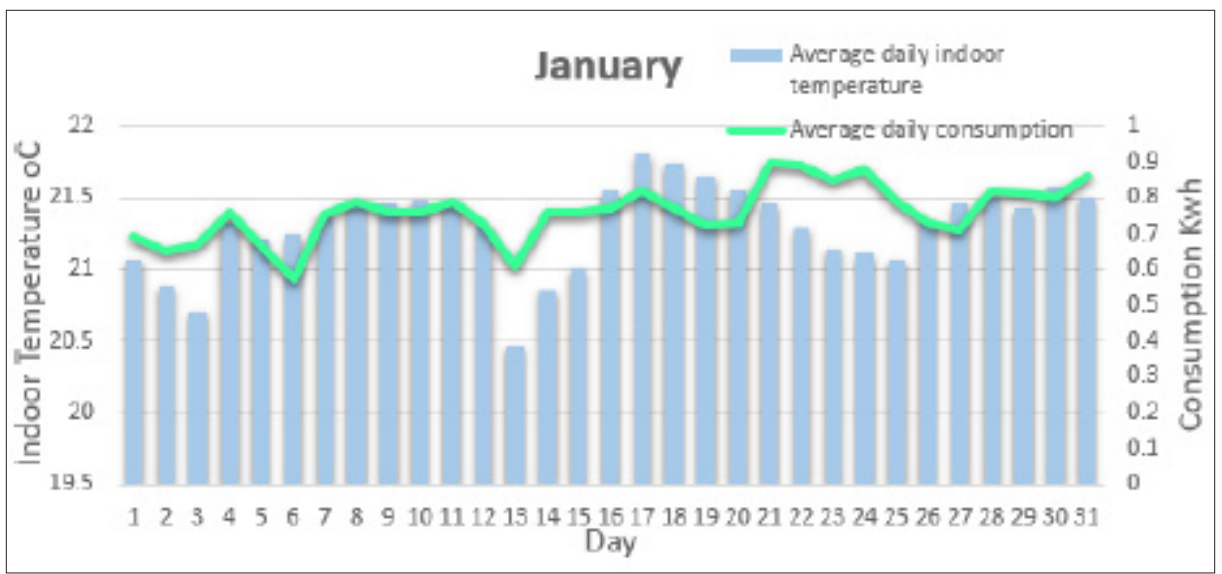

Figure 5: Average indoor temperature and consumption in January.

\section{Acknowledgement}

This work is partially supported by the "enCOMPASScollaborative recommendations and adaptive control for personalized energy saving" project funded by the EU H2020 Programme grant agreement no.723059.

\section{References}

1. Amin SM, Bruce FW (2005) Toward a smart grid: power delivery for the $21^{\text {st }}$ century. IEEE Power and energy magazine 3(5): 34-41.
2. Reddy TL, Thomson RJ (2014) Environmental, social and economic sustainability: implications for actuarial science. School of Statistics and Actuarial Science, University of the Witwatersrand, South Africa.

3. Zheng, Jixuan, David WG, Li L (2013) Smart meters in smart grid: An overview. 2013 IEEE Green Technologies Conference (Green Tech).

4. Yi-Ling H, Hai-Zhen M, Guang-Tao D, Shi Jun (2014) Influences of urban temperature on the electricity consumption of Shanghai. Advances in Climate Change Research 5(2): 74-80.

5. Salehizade, Ali Akbar (2015) Analysis of temperature changes on electricity consumption in fars province. Mediterranean Journal of Social Sciences 6(3): 610. 